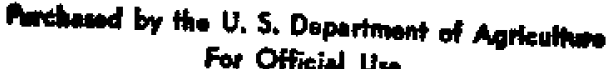

Reprinted from AGRONOMY JOURNAL

Vol. 64, Nov.-Dec. 1972, p. 736-738

\title{
Influence of Seed Orientation on Bean Seedling Emergence ${ }^{1}$
}

\section{S. A. Bowers and C. W. Hayden ${ }^{2}$}

\section{ABSTRACT}

Observation from an unrelated field bean experiment indicated that certain seed orientations might reduce emergence. Consequently, studies were initiated to determine if orientation variations occur in planting and if these variations influence emergence.

Orientation of bean seeds, dropped into both " $v$ " and flat-bottom furrows, were classified and tabulated. In "V' furrows almost all orientations were possible; $36 \%$ assumed the "lay-flat" orientation. In the flat-botton furrow $85 \%$ of the beans were in the "lay-flat" position. The influence of 11 different seed orientations on emergence was evaluated in greenhouse studies. With crusted soils seeds planted "hypocotyl end down" produced significantly less emerged seedlings (1\% level) and a lower emergence rate. Orientation effects were observed to a lesser degree in noncrusted soils.

The adverse influence of "hypocotyl end down" orientalions was attributed to seed rotation within the soil. For controlled plantings the "lay-flat" orientation is recommended due to both its high frequency of occurrence and high emergence.

Additional key words: Soil crust, Seed rotation.

T $\mathrm{N}$ the past, reduced or retarded seedling emergence I has generally been attributed to soil crusts, insufficient soil moisture, low soil temperature, nonviable seed, etc. Recent observations from an unrelated bean field experiment indicated a possible relationship between emergence and seed orientation. In that experiment, field beans were planted at exact intervals by punching holes in the soil with a pencil and inserting the seed. Except for a thin soil crust, conditions appeared favorable for both germination and emergence; emergence, however, was approximately $50 \%$. On reconsideration of the planting procedure, it was evident that the narrowness of the holes caused the seeds to be planted "on end" rather than in their normal horizontal position. Furthermore, probabilities were that $50 \%$ were planted "hypocotyl end down" and 50\% "hypocotyl end up."

The apparent coincidence of $50 \%$ emergence by beans planted in this manner caused speculation concerning the influence of seed orientation on emergence. The series of small, sequential experiments reported in this study were initiated to determine possible relationships between orientation and emergence.

\section{EXPERIMENTAL PROCEDURE}

In planting beans, whether by hand or machine, seed is dropped into a furrow and covered by soil. Fig. 1 shows 11 different possible orientations considered. Experiment 1 was concerned with the frequency at which these various orientations occur. Fifty seeds were individually dropped from a $30-\mathrm{cm}$ height into both a " $\mathrm{V}$ " and a flat-bottomed furrow; each seed

${ }^{1}$ Contribution from the Northwesc Branch, Soil and Water Conservation Research Division, Agricultural Research Service, USDA; Idaho Agricultural Experiment Station cooperating. Received March 8, 1972.

'Soil Scientist, Water Quality Management Laboratory, Durant, Oklahoma 74701 (formerly located at Snake River Conservation Research Center); and Agricultural Research Technician (Soils), Snake River Conservation Research Center, Kimberly, Idaho. was classified as to the resulting orientation. The process was repeated five times with each type furrow.

In Experiment 2, three bean varieties, Pinto UI-114, Great Northern UI-59, and Dark Red Kidney, were planted in nine different orientations; orientations 4 and 6 (Fig. 1) were inadvertently omitted. Seeds were planted four to a row in boxes $70 \times 55 \times 15 \mathrm{~cm}$. Plant spacing was $10 \mathrm{~cm}$, row spacing 12.5 $\mathrm{cm}$, and the planting depth was $5 \mathrm{~cm}$. All four seeds within each row were in the same orientation. The soil, Poreneuf silt loam, was packed to an approximate $1.3 \mathrm{~g} / \mathrm{cm}$ \&bulk densityAfter planting, the boxes were placed in a rain tower and sprinkled with approximately $3.75 \mathrm{~cm}$ of water, Boxes were then placed in a greenhouse where emergence counts and times of emergence were recorded. During the emergence process, crusts from 2 to $4 \mathrm{~cm}$ thick were formed. The statistical design was a randomized complete block and analyzed as a $3 \times 9$ factorial with fout replications.

Experiment 3 was initiated because oxientations 4 and 6 were. omitted in the previous experiment. The design was a completely randomized block with 1 I orientations and 5 replications. The pIanting and sprinkling procedure was identical to that used in the above experiment. Here, however, only emergence counts were taken. The variety planted was 'Pinto UI-114,"

In Experiment 4, the worst orientation (No. l) from Experiments 2 and 3 was compared, under noncrusted conditions, with two of the better orientations (Nos. 2 and 11). The only procedure differences were that sufficient water was added to the lower $10 \mathrm{~cm}$ to bring the whole soil mass to field capacity; the air-dried surface $5 \mathrm{~cm}$ was then added. In addition, six seeds were planted in each row. The design was a completely randomized block of three orientations and six replications.

Since in all the above sequential experiments the emergence counts were small whole numbers, the analysis was based on the $\sqrt{\mathrm{X}+1}$ transform, where $\mathrm{X}$ was the emergence count. Duncan's nultiple range test was used for mean separation in Experiments 2-4.

\section{RESULTS AND DISCUSSION}

Table 1 shows the average number of beans that fell into each of the 11 orientations. While no statistical analysis was made, the data show that in " $V$ " shaped furrows almost all orientations are possible. As anticipated, the most frequent was No. 11, the "lay-flat" orientation; approximately $36 \%$ of the beans assumed this orientation. In the "flat-bottomed" furrow, approximately $85 \%$ fell into orientation 11 , The oblong and flat shape of the bean varieties used predispose them to a horizontal orientation. Obviously a different frequency distribution could be

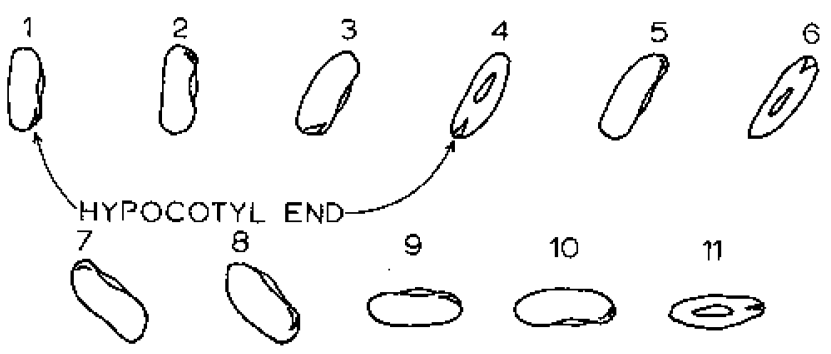

Fig. 1. Bean seed orientations.

Table 1. Average distribution of 50 beans dropped in "V" and flat-bottomed furrows.

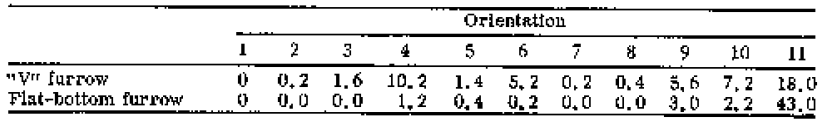


anticipated for broadcast beans or beans dropped in holes. The influence of covering the seed and packing the soil is not known.

Table 2 gives the average emergence counts from Experiments 2 to 4 . 'Actual emergence counts are shown rather than the $\sqrt{\mathrm{X}+1}$ transform used in the statistical analysis. In Experiment 2, the analysis of variance and associated " $F$ " test showed significant differences at the $1 \%$ level, due both to seed orientation $\left(\mathbf{F}_{9,78}=6.09 * *\right)$ and varieties $\left(\mathbf{F}_{2,78}=20.98^{* *}\right)$. They failed to show a significant difference due to the variety $\times$ orientation interaction. Separation of means showed 'Great Northern UI.59' had significantly lower emergence (5\% level) than either Pinto UI114 or 'Dark Red Kidney;' no significant emergence differences were detected between the latter two.

Separation of orientation means showed that seeds with "hypocotyl end downward" (Nos. 1, 3, and 8) were significantly lower in emergence (5\% level) than both "hypocotyl end upward" (Nos. 2, 5, 7) and the normal "lay-flat" orientation (No. 11). The "layflat" and "hypocotyl end upward" orientations were not significantly different.

Fig. 2 shows the cumulative emergence versus time for all nine orientations, regardless of variety. The curves naturally separate into three separate groups: "hypocotyl ends upward" and "lay-flat," those set on edge, and "hypocotyl ends downward." The rate of emergence was greatest for the first group and least for the last.

The emergence time for all orientations was unusually long, probably because of low temperature and soil crust resistance. These experiments were conducted during the late fall and winter in the greenhouse where temperatures were lower than those normally occurring during emergence in the field.

The Experiment 3 emergence data showed significant differences at the $1 \%$ level due to seed orientation $\left(F_{10,44}=4.44 * *\right)$. The trend was similar to that of Experiment 2, except for orientations 2 and 3 . In Experiment 2, these were respectively the best and next to poorest emergers, but in Experiment 3 they were ranked in the middle of the series (Table 2). Reasons for the shift in rank are not known, but might be due to the small number of seeds per replication. However, the results still indicate that seeds oriented with "hypocotyl end downward" are poorer emergers than those with "hypocotyl end upward" or the "lay-flat" position. This is particularly true for orientations 1 and 8 , which had the lowest emergence in both studies.

Results from Experiment 4 (Table 2) show that even under noncrusted conditions orientation caused a significant difference in emergence $\left(\mathrm{F}_{2,15}=3.68^{*}\right)$.
Orientation $l$ had a lower emergence than orientation 2, but the difference was not significant. Orientation 11 showed significantly greater emergence than orientation 1, but not greater than orientation 2 .

The results of the experiments show that in planting beans various orientations may occur, particularly when hand-seeding. The resulting orientations are a function of the surface configuration. If dropped on a smooth, flat surface, the beans orient themselves in a "lay-flat" position (No. 11). The likelihood of beans standing exactly on end is remote, particularly in mechanized agriculture. However, in some underdeveloped countries where a "slash and burn" agriculture is practiced, planting is frequently done by dropping seeds into a hole made by a stick. In such cases, "stand-on-end" orientations could occur frequently.

Despite some contradiction, the experimental results show that orientation of seeds with "hypocotyl end downward" reduces both the number and rate of seedling emergence as compared with "hypocotyl end upward" and "lay-flat" orientations. While the influence was more pronounced in crusted soils, it was also evident in noncrusted soils.

Decrease in emergence and emergence rate with "hypocotyl end downward" orientations is probably related to seed rotation. Bean cotyledons always emerge from the soil hypocotyl end first. If planted in one of the "hypocotyl end downward" orientations, the seed must rotate before emergence takes

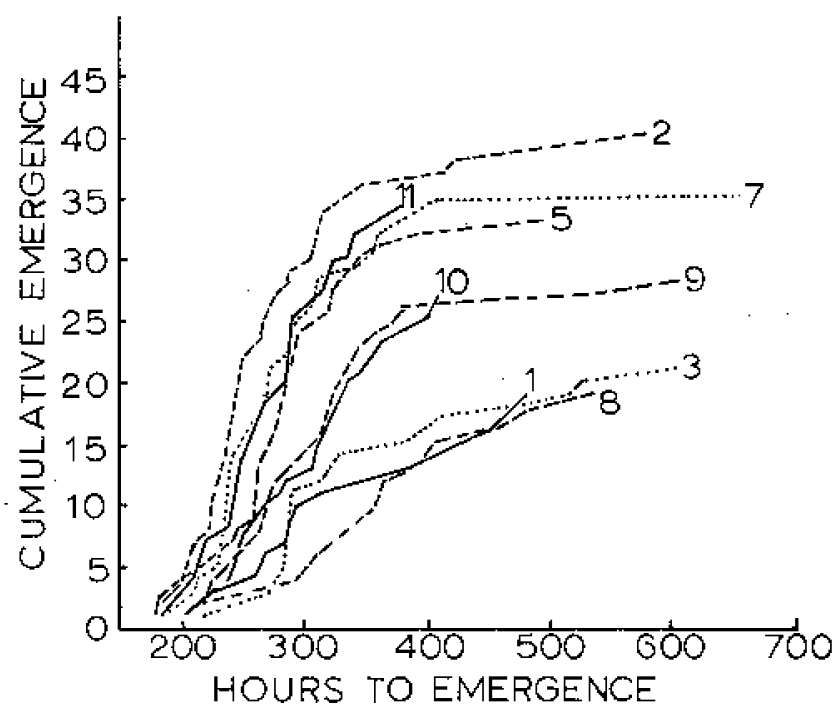

Fig. 2. Cumulative emergence of bean seedlings vs. hours to emergence. Fach curve is identified by the orientation number of the planted seed.

Table 2. Emergence counts from crusted and noncrusted soils.

\begin{tabular}{|c|c|c|c|c|c|c|c|c|c|c|c|c|}
\hline \multirow{2}{*}{$\begin{array}{l}\text { Experiment } \\
\text { and trentment. }\end{array}$} & \multicolumn{11}{|c|}{ Orientation } & \multirow[b]{2}{*}{ Average } \\
\hline & 1 & 2 & 3 & 4 & 5 & 6 & 7 & $B$ & 9 & 10 & 11 & \\
\hline $\begin{array}{l}\text { Fxp. } 2 \text { (crusted solI)* } \\
\text { P1nto LI- } 114 \\
\text { Gruth Northern UI-59 } \\
\text { Eirk Rigd Kldney }\end{array}$ & $\begin{array}{l}2,0 \\
0,8 \\
2,0\end{array}$ & $\begin{array}{l}3.3 \\
3.5 \\
3.2\end{array}$ & $\begin{array}{l}2.5 \\
0.3 \\
2.5\end{array}$ & $\begin{array}{l}--- \\
--- \\
\cdots--\end{array}$ & $\begin{array}{l}2.8 \\
1.8 \\
3.6\end{array}$ & $\begin{array}{l}-- \\
-- \\
\dot{-}-\end{array}$ & $\begin{array}{l}3.0 \\
2.2 \\
3.5\end{array}$ & $\begin{array}{l}1,0 \\
1,0 \\
2,0\end{array}$ & $\begin{array}{l}3.0 \\
1.0 \\
3.0\end{array}$ & $\begin{array}{l}3.0 \\
1.5 \\
2.3\end{array}$ & $\begin{array}{l}3,0 \\
2,7 \\
2,8\end{array}$ & $\begin{array}{l}2,7 \mathrm{~A} \\
1.6 \mathrm{~b} \\
2,8 \mathrm{a}\end{array}$ \\
\hline Average & 1.60 & $3,3 \mathbf{n}$ & $1.8 \mathrm{c}$ & -- & 2.8 ath & --- & $2.9 \mathrm{ab}$ & 1,60 & 2.3 bo & $2,3 \mathrm{bc}$ & 2. $B \mathrm{ab}$ & \\
\hline $\begin{array}{l}\text { Fixp, } 3 \text { (cruated sodl) } \dagger \\
\text { plnto UI-114 }\end{array}$ & $0.8 \mathrm{~d}$ & 2,2 abe & $2.2 \mathrm{abo}$ & $2,0 \mathrm{bec}$ & $3.6 \%$ & $3.6 \mathrm{a}$ & $3.2 \mathrm{ab}$ & $1.2 \mathrm{od}$ & $2.0 \mathrm{bo}$ & 2,4 thos & $\$, 2 \mathrm{ab}$ & \\
\hline 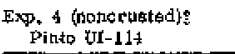 & $4.3 \mathrm{~b}$ & $5.5 \mathrm{ab}$ & --- & $n=$ & -- & --- & --- & $=$ & --- & --- & $5.8 \mathrm{a}$ & \\
\hline
\end{tabular}




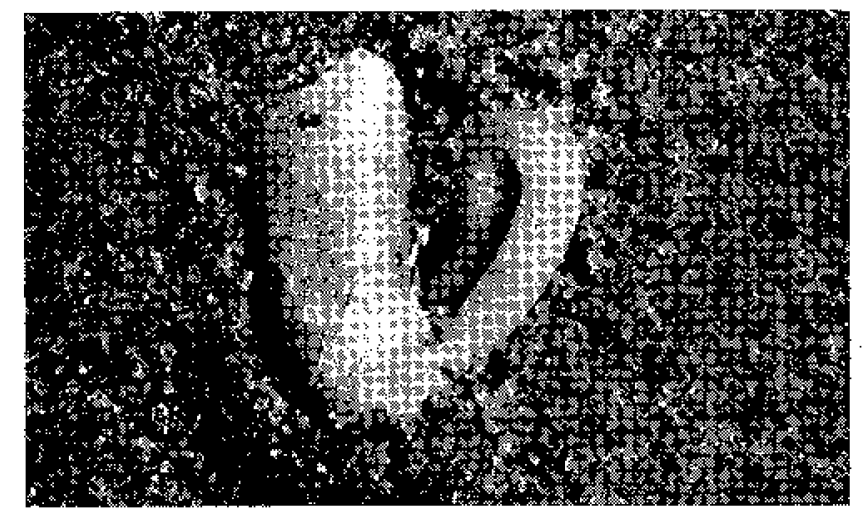

Fig, 3. Emerging bean seedling of orientation 1 (hypocotyl end down).
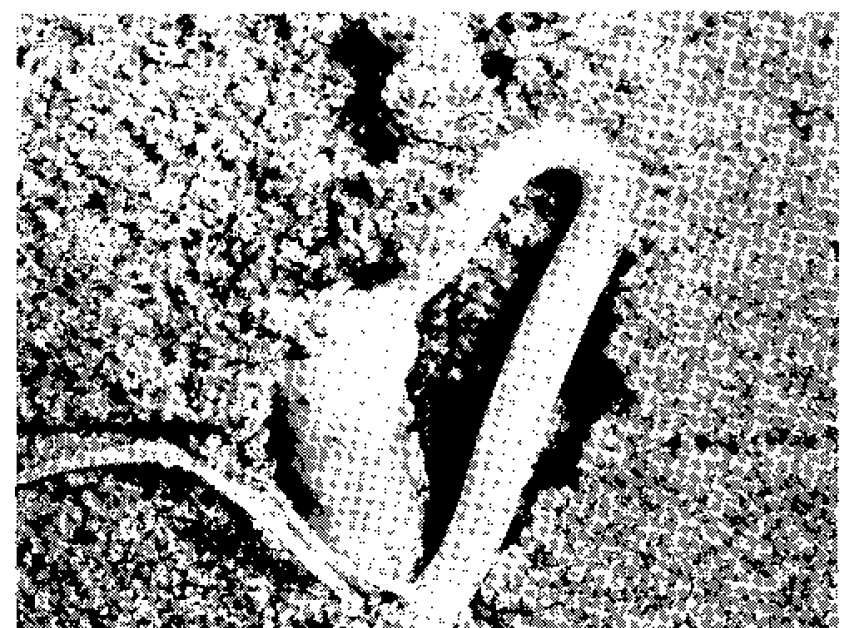

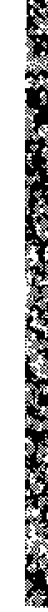
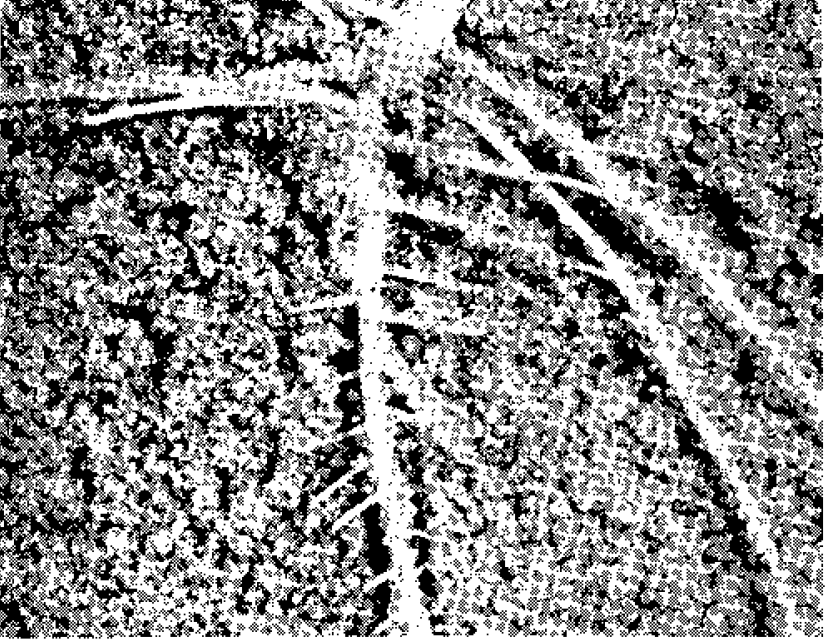

Fig. 4. Emerging bean seedling of orientation 2 (hypocotyl end up).

place; rotation, depending on the particular downward orientation, may approach $180^{\circ}$. In tightly packed soils, there could be considerable resistance to rotation. If, in addition, there is a crust, the seedling may not have the capability to both rotate and penetrate.

Fig. 3, 4, and 5 show emerging beans of orientations 1,2 , and 11 , respectively; all are at approximately the same stage of development. These beans were planted in a sand-filled box of which one end was a removable plastic observation window. With

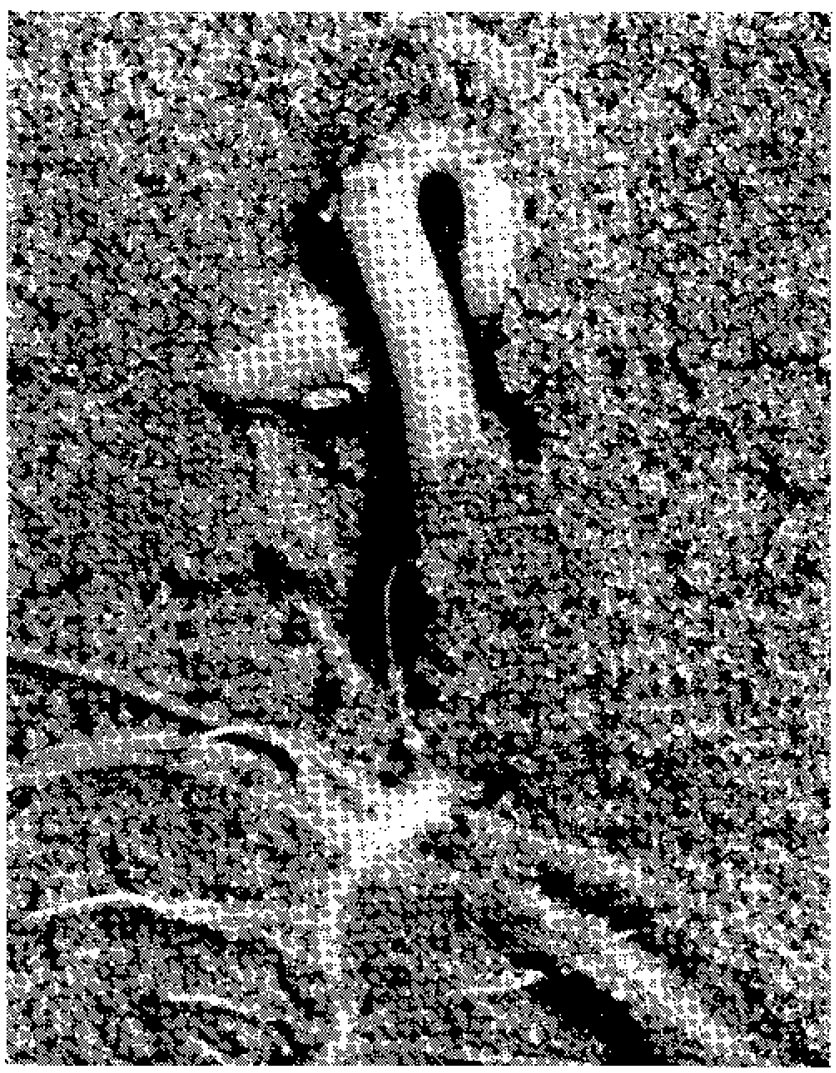

Fig. 5. Emerging bean seedling of orientation 11 (lay-fIat).

both the "lay-flat" (No. 11) and "hypocotyl end straight up" (No. 2), the plumular hook is breaking a path through which the cotyledons will follow. A pressure ridge above the plumular hook of the "lay-flat" orientation is clearly discernible (Fig. 5). With the "hypocotyl end straight-down" (No. 1), a pressure ridge is downward and to the side opposite from which emergence must proceed. This downward ridge is obviously caused by pressure exerted by the rotating seed. Exhuming unemerged seedlings of orientation 1 showed, in some instances, cotyledons that were wedged against their own stem and roots and were unable to turn. The resulting stress caused breaks in hooks and stems.

The rotation time may be a factor in decreasing emergence through crust. If rotation delays penetration, then conceivably this allows additional time for the crust to dry, strengthen, and further resist an already weakened seedling. Furthermore, this rotation time probably contributes to nonuniformity in stand, bloom, and fruit set, even under noncrusted conditions. Where green and lima beans are grown commercially, rotation time might, by itself, reduce yields as it is preferable to harvest fields only once.

The data presented in this paper, but without the benefit of field trials, indicate that planting bean seeds in one of the more favorable orientations could result in greater emergences, emergence rates, and uniform stands, particularly where soil is crusted. Probably the "lay-flat" orientation (No. I1) is preferable since, due to the bean configuration, it is the easiest to achieve and consistently one of the better emergers. The problem of how to achieve uniform seed orientation is presently under consideration. 